\title{
BEDA EFEKTIVITAS ELEKTROAKUPUNKTUR DENGAN TENS TERHADAP NYERI DAN FLEKSIBILITAS LUMBAL PADA PASIEN NYERI PUNGGUNG BAWAH MYOGENIK
}

\author{
Saifudin Zuhri, Marti Rustanti \\ Kementerian Kesehatan Politeknik Kesehatan Surakarta Jurusan Fisioterapi
}

Abstrack : Lower Back Pain, Electroacupuncture, TENS, Pain, Lumbar Flexibility. Myogenic lower back pain (LBP) is a prevalence that many experienced individuals who perform daily activities. Physiotherapy technology for myogenic LBP in the form of TENS is given more clinically than electroacupuncture that has not been effectively socialized. Objective: To compare the effectiveness of TENS with electroacupuncture for pain and lumbar flexibility of myogenic LBP patients. Quasi experimental research with two groups pre and post test design. The subjects of the study were myogenic LBP patients who met the study criteria. Inclusion criteria include: (1) age 50 - 70 years, (2) willing to be the subject of research. Exclusion criteria: (1) suffer myogenic LBP followed by other disorders, (2) pacemaker use, (3) impaired sensibility, (4) malignancy in the lower back. Criteria for drop out: (1) not following therapy program more than 3 times, (2) experiencing worsening condition, (3) not present during final evaluation of research. Data were collected directly at the start of the study (pre test), pain was measured by VAS and flexibility was measured by schober test. Data were analyzed with SPSS 11.5 for windows. The results of pre-post test different test in group I with Wilcoxon test, obtained $p$ value $=0.005(p<0.05)$. Test of pre-post test in group II with Wilcoxon test, got $\mathrm{p}$ value $=0,004(\mathrm{p}<0.05)$. Test of difference of post test in group I and group II using Mann-Whitney test, got value $p=0,017(\mathrm{p}<0.05)$. The result of change of mean difference of VAS value of pre and post therapy in group I was $45 \mathrm{~mm}$ while in group II was $31 \mathrm{~mm}$. Conclusions: (1) there was an effect of electroacupuncture therapy on the decrease of pain in myogenic LBP patients before administered by William Flexion Exercise $(p=0,005)$; $(2)$ there was effect of TENS therapy on pain reduction in myogenic LBP patients before given William Flexion Exercise $(\mathrm{p}=0.004),(3)$ there was a difference in effect between electro-acupuncture therapy and TENS therapy on pain reduction in patients with myogenic LBP prior to William Flexion Exercise ( $p=0.017)$, (4) electroacupuncture was more effective than TENS for pain reduction in patients Myogenic LBP before administered by William Flexion Exercise was compared with the mean difference between pre and post I group VAS values greater than group II (group I $=45 \mathrm{~mm}$, group II $=31 \mathrm{~mm}$ ).

Keywords: Lower Back Pain, Electroacupuncture, TENS, Pain, Lumbar Flexibility

Abstrak: Nyeri Punggung Bawah, Elektroakupunktur, TENS, Nyeri, Fleksibilitas Lumbal. Nyeri punggung bawah (NPB) myogenik merupakan prevalensi yang banyak dialami setiap individu yang melakukan aktifitas sehari-hari. Teknologi fisioterapi untuk NPB myogenik berupa TENS lebih banyak diberikan di klinis dibandingkan elektroakupunktur yang belum tersosialisasi secara efektif. Tujuan penelitian untuk 
membandingkan efektifitas TENS dengan elektroakupunktur untuk nyeri dan fleksibilitas lumbal penderita NPB myogenik. Penelitian berupa quasi eksperimen dengan two group pre and post test design. Subyek penelitian adalah penderita NPB myogenik yang memenuhi kriteria penelitian. Kriteria inklusi meliputi: (1) usia $50-70$ tahun, (2) bersedia menjadi subyek penelitian. Kriteria eksklusi: (1) menderita NPB myogenik diikuti gangguan lain, (2) memakai pacu jantung, (3) mengalami gangguan sensibilitas, (4) ada malignansi di punggung bawah. Kriteria drop out: (1) tidak mengikuti program terapi lebih dari 3 kali, (2) mengalami perburukan kondisi, (3) tidak hadir saat evaluasi akhir penelitian. Data dikumpulkan secara langsung pada awal penelitian (pre test), nyeri diukur dengan VAS dan fleksibilitas diukur dengan schober test. Data dianalisis dengan SPSS 11.5 for windows. Hasil Uji beda pre - post test pada kelompok I dengan Wilcoxon test, didapatkan nilai $\mathrm{p}=0,005(\mathrm{p}<0.05)$. Uji beda pre post test pada kelompok II dengan Wilcoxon test, didapatkan nilai $\mathrm{p}=0,004(\mathrm{p}<0.05)$. Uji beda post test pada kelompok I dan kelompok II menggunakan Mann-Whitney test, didapatkan nilai $\mathrm{p}=0,017(\mathrm{p}<0.05)$. Hasil perubahan selisih rerata nilai VAS pre dan post terapi pada kelompok I adalah $45 \mathrm{~mm}$ sedangkan pada kelompok II adalah $31 \mathrm{~mm}$. Kesimpulan: (1) ada pengaruh terapi elektroakupunktur terhadap penurunan nyeri pada pasien NPB myogenik sebelum diberikan William Flexion Exercise $(\mathrm{p}=0,005),(2)$ ada pengaruh pemberian terapi TENS terhadap penurunan nyeri pada pasien NPB myogenik sebelum diberikan William Flexion Exercise $(\mathrm{p}=0,004),(3)$ ada perbedaan pengaruh antara pemberian terapi elektroakupunktur dengan pemberian terapi TENS terhadap penurunan nyeri pada pasien NPB myogenik sebelum diberikan William Flexion Exercise $(\mathrm{p}=0,017)$, (4) pemberian elektroakupunktur lebih efektif daripada pemberian TENS terhadap penurunan nyeri pada pasien NPB myogenik sebelum diberikan William Flexion Exercise dibuktiklan dengan selisih rerata nilai VAS pre dan post kelompok I lebih besar daripada kelompok II (kelompok I $=45 \mathrm{~mm}$, kelompok II =31 mm).

Kata Kunci: Nyeri Punggung Bawah, Elektroakupunktur, TENS, Nyeri, Fleksibilitas Lumbal

\section{PENDAHULUAN}

Di Indonesia, hasil penelitian yang dilakukan Pokdi Nyeri PERDOSSI di Poliklinik Neurologi Rumah Sakit Cipto Mangunkusumo (RSCM) pada tahun 2002, menemukan bahwa proporsi penderita nyeri punggung bawah sebanyak $15,6 \%$ pada kelompok umur 18-78 tahun. Angka ini berada pada urutan kedua tertinggi sesudah sefalgia dan migren yang mencapai $34,8 \%$. Hasil penelitian secara nasional pada 14 kota di Indonesia oleh kelompok studi Nyeri PERDOSSI tahun 2002 juga ditemukan 18,13\% penderita nyeri punggung bawah
(Huldani, 2012).
Salah satu gangguan yang
menyebabkan nyeri dan penurunan
fleksibilitas pada punggung yang banyak
dialami masyarakat adalah nyeri
punggung bawah miogenik sehingga
gangguan ini banyak dijumpai di
masyarakat. Nyeri punggung bawah
miogenik merupakan salah satu bentuk
gangguan pada struktur otot punggung
umumnya terjadi karena trauma, bisa
berupa strain, spasme otot dan strain 
ligamen di punggung bawah (Prasodjo, 2002).

Fisioterapi memiliki peran penting dalam penatalaksanaan nyeri punggung bawah. Beberapa modalitas fisioterapi untuk menangani kasus ini, di mana di klinik sering dijumpai dominasi modalitas TENS yang diberikan pada kasus nyeri punggung bawah terutama untuk penurunan nyeri. Pada penelitian berjudul Randomised Controlled Trial Comparing the Effectiveness of Electroacupuncture and TENS for Low Back Pain, dijelaskan bahwa elektroakupunktur memiliki efek menurunkan nyeri pada pasien nyeri punggung bawah. Jadi kedua intervensi ini memiliki efek yang sama terhadap penurunan nyeri. Di samping itu aplikasi back exercise pada tindakan fisioterapi juga diberikan setelah aplikasi TENS, sehingga dapat meningkatkan fleksibilitas lumbal.

Transcutaneous electrical nerve stimulation (TENS) merupakan salah satu modalitas yang sering digunakan untuk mengatasi nyeri oleh para fisioterapis di Indonesia. TENS mampu mengaktivasi serabut saraf berdiameter besar maupun berdiameter kecil yang akan menyampaikan berbagai informasi sensoris ke sistem saraf pusat. TENS sering disebut sebagai teknik analgesik non-invasif untuk meringankan nyeri nociceptive dan nyeri neuropatik. Stimulasi listrik yang diberikan pada intervensi ini cukup jauh dari jaringan yang cidera ataupun rusak, sehingga jaringan yang menimbulkan nyeri tetap efektif untuk memodulasi nyeri. Selama diberikannya intervensi TENS, arus listrik yang berdenyut dihasilkan oleh generator denyut portabel dan disampaikan ke permukaan kulit dengan bantalan yang disebut elektroda. TENS memberikan stimulasi arus yang berulang dengan menggunakan pulsa durasi 50-250 ms dan frekuensi 1-200 Hz (Johnson, 2015).

Metode stimulasi listrik yang menggunakan jarum dikenal dengan istilah elektroakupunktur. Di sini jarum ditusukkan terhadap area nyeri yaitu trigger point (dalam bahasa cina disebut ah-shi point). Kenyataan efek dari elektroakupunktur ini hampir sama dengan TENS, namun pada elektroakupunktur melalui jarum yang ditusukkan dan dialiri arus listrik itu dianggap dapat meningkatkan kenyamanan analgesia, mengurangi intensitas nyeri dan meningkatkan kenyamanan psikologis, aktivitas, dan kualitas tidur pada pasien nyeri punggung bawah miogenik (Fox dan Melzack, 1984; Sator-Katzenschlager et al, 2004).

\section{METODE PENELITIAN}

Penelitian ini menggunakan metode eksperimental semu dengan rancangan penelitian two group pretestpost test design. Penelitian berlangsung bulan Februari sampai Mei 2016. Penelitian dilakukan di Klinik Sunafa, Jl. Kapt Adisumarmo, Tohudan, Colomadu, Surakarta. Subyek penelitian dari pasien nyeri punggung bawah myogenik yang memenuhi kriteria penelitian, yang berobat ke klinik Sunafa, Tohudan Colomadu, Surakarta.

Kriteria dalam penelitian meliputi: kriteria inklusi, (2) eksklusi, dan (3) drop out. Kriteria inklusi meliputi: (1) subyek NPB miogenik, (2) usia 18-70 tahun, (3) bersedia menjadi subyek penelitian. Kriteria ekslusi meliputi : (1) NPB miogenik diikuti gangguan yang lain (2) memakai alat pacu jantung, (3), mengalami gangguan sensibilitas (4) adanya malignansi di punggung bawah. 
Kriteria drop-out meliputi : (1) tidak mengikuti program terapi $>3 \mathrm{kali}$

Semula peneliti meminta ijin pada Klinik Fisioterapi Sunafa, Tohudan, Colomadu, Surakarta. Selanjutnya peneliti melakukan pendekatan pada pasien untuk mendapatkan persetujuan sebagai subyek penelitian dengan mengisi informed consent.

Alat-alat dan bahan-bahan penelitian yang dipersiapkan antara lain: (1) formulir penelitian, formulir persetujuan, dan alat tulis, (2) alat elektroakupunktur dari SDZ-III Nerve and Muscle Stimulator, jarum akupunktur, kapas, alkohol, (3) alat TENS dari SDZIII Nerve and Muscle Stimulator, (5) blanko VAS dan Schober test

Cara kerja penelitian adalah : (1) pengambilan subyek sesuai kriteria inklusi dan eksklusi, (2) subyek yang diterima diminta untuk mengisi formulir persetujuan penelitian dan menandatanganinya, (3) subyek diberi penjelasan tentang tujuan dan manfaat dari penelitian

Cara pengambilan subyek penelitian adalah subyek dikelompokkan menjadi 2 kelompok yaitu kelompok I dengan perlakuan terapi elektroakupunktur sedangkan kelompok II dengan TENS. Subyek NPB miogenik ganjil dimasukkan kelompok I, dan subyek urut genap dimasukkan dalam kelompok II, dan seterusnya. Setiap subyek diberikan terapi 6 kali per 2 minggu, seminggu 3 kali.

Kemudian sebelum perlakuan diberikan, masing-masing subyek diukur nyeri dan fleksibilitas lumbal sebagai data awal (pre test) dan setelah terapi yang ke6 , masing-masing subyek dievaluasi nyeri dan fleksibilitas lumbal sebagai data post test.
Data awal subyek penelitian sebelum diberikan EAP dan TENS dilakukan uji normalitas data yaitu apabila subyek lebih dari 50 maka uji normalitas dengan Kolmogorov-Smirnov test dan jika kurang dari 50 maka uji normalitas dengan Shapiro-wilk test.

Jika subyek lebih dari 30 dan uji normalitas data terpenuhi maka uji statistik dengan uji parametrik yaitu uji t, namun jika tidak terpenuhi, maka diuji dengan non parametrik test .yaitu uji intra kelompok dengan Wilcoxon test dan uji inter kelompok dengan Mann-Whitney test. Uji dinyatakan ada pengaruh atau ada beda jika didapatkan $\mathrm{p}<0,05$.

\section{HASIL PENELITIAN}

Pelaksanaan penelitian sekaligus pengambilan data dilakukan bulan Juni sampai Agustus 2016. Penelitian bertujuan untuk mengetahui perbedaan efektivitas elektroakupunktur dan TENS terhadap nyeri dan fleksibilitas lumbal pada pasien nyeri punggung bawah myogenik di mana setiap subyek setelah perlakuan diberikan William Flexion Exercise.

Pada proses awal penelitian, diperoleh subjek yang memenuhi kriteria inklusi berjumlah 51 orang. Seluruh subyek penelitian dibagi menjadi dua kelompok yaitu 26 orang masuk kelompok I yang memperoleh terapi berupa elektroakupunktur dan William Flexion Exercise dan 25 orang masuk kelompok II yang memperoleh terapi berupa TENS dan William Flexion Exercise. Selama proses penelitian berjalan, terdapat 2 subjek yang dinyatakan drop out karena tidak memenuhi program terapi sebanyak $6 \mathrm{kali}$ pertemuan yang terdiri dari 1 subjek dari kelompok I yang memperoleh terapi 
berupa elektroakupunktur dan William Flexion Exercise dan 1 subjek dari kelompok II yang memperoleh terapi berupa TENS dan William Flexion Exercise. Sehingga subjek penelitian ini berjumlah 49 subjek, yaitu 25 subjek di kelompok I dan 24 subjek di kelompok II.

Adapun karakteristik subyek penelitian meliputi: (1) usia, (2) indeks massa tubuh, (3) jenis kelamin dan (4) pekerjaan.

1. Karakteristik subjek penelitian berdasarkan usia

Distribusi subjek berdasarkan usia pada kelompok I, didapat data usia minimal 26 tahun, usia maksimal 69 tahun dengan rerata usia 58,60 tahun. Sedangkan pada kelompok II, usia minimal 50 tahun, usia maksimal 70 tahun dengan rerata usia 61,30 tahun.

Tabel 1

\begin{tabular}{ccc}
\multicolumn{3}{c}{$\begin{array}{c}\text { Distribusi Subjek Penelitian } \\
\text { Berdasarkan Usia Pada Kelompok I } \\
\text { dan Kelompok II }\end{array}$} \\
\cline { 2 - 3 } Usia & $\begin{array}{c}\text { Kelompok I } \\
\mathbf{n}=\mathbf{1 0}\end{array}$ & $\begin{array}{c}\text { Kelompok II } \\
\mathbf{n}=10\end{array}$ \\
& &
\end{tabular}

\begin{tabular}{ccc}
\hline Usia minimal & 50 & 50 \\
Usia & 66 & 70 \\
maksimal & & \\
Rerata & 58,60 & 61,30 \\
Standar & $\pm 5,160$ & $\pm 7,587$ \\
deviasi & & \\
\hline
\end{tabular}

2. Karakteristik subjek penelitian berdasarkan indeks massa tubuh

Karakteristik subjek penelitian berdasarkan indeks massa tubuh pada penelitian ini didapatkan 3 kriteria yaitu, underweight, normal, dan overweight. Dari data kedua kelompok yang telah didapatkan tidak ada indeks massa tubuh underweight, indeks massa tubuh normal sebanyak 11 orang dan indeks massa tubuh overweight sebanyak 9 orang.
Keadaan indeks massa tubuh pada masing - masing kelompok adalah sebagai berikut (1) kelompok I indeks massa tubuh normal terdiri dari 5 subjek dan indeks massa tubuh overweight terdiri dari 5 subjek, (2) kelompok II indeks massa tubuh normal terdiri dari 6 subjek dan indeks massa tubuh overweight terdiri dari 4 subjek. Sehingga disimpulkan bahwa distribusi subjek penelitian berdasarkan indeks massa tubuh pada kedua kelompok lebih dominan pada kriteria normal.

\section{Tabel 2}

Distribusi Subjek Penelitian Berdasarkan Indeks Massa Tubuh Pada Kelompok I Dan Kelompok II

$\begin{array}{cccc}\text { IMT } & \begin{array}{c}\text { Kelompo } \\ \mathbf{k} \text { I } \\ \mathbf{n}=\mathbf{1 0}\end{array} & \begin{array}{c}\text { Kelompo } \\ \mathbf{k} \text { II }\end{array} & \begin{array}{c}\text { Jumla } \\ \mathbf{h}\end{array} \\ & & \mathbf{1 0} & \\ & & & \end{array}$

\begin{tabular}{cccc}
\hline Underweigh & 0 & 0 & 0 \\
$t$ & & & \\
Normal & 5 & 6 & 11 \\
Overweight & 5 & 4 & 9 \\
Jumlah & 10 & 10 & 20 \\
\hline
\end{tabular}

3. Karakteristik subjek penelitian berdasarkan jenis kelamin

Karakteristik subjek penelitian berdasarkan jenis kelamin tidak dilakukan analisis statistik karena subjek dari kedua kelompok berjenis kelamin sama, yaitu perempuan.
4. Karakteristik subjek penelitian berdasarkan pekerjaan

Karakteristik subjek penelitian berdasarkan pekerjaan tidak dilakukan analisis statistik karena subjek dari kedua kelompok rata-rata berprofesi sebagai ibu rumah tangga.

Pengukuran pre test dengan VAS pada kelompok I (elektroakupunktur dan WFE) didapatkan hasil nilai VAS minimal $60 \mathrm{~mm}$, nilai VAS maksimal $80 \mathrm{~mm}$ dengan rerata $71,00 \mathrm{~mm}$, sedangkan pada kelompok II (TENS dan WFE) didapatkan 
hasil nilai VAS minimal $60 \mathrm{~mm}$, nilai VAS maksimal $80 \mathrm{~mm}$ dengan rerata 67,00. Dari data tersebut didapat rerata nilai VAS sebelum perlakuan pada kedua kelompok tidak jauh berbeda, yaitu selisih $4 \mathrm{~mm}$ lebih besar pada kelompok I yang diberikan terapi elektroakupunktur dan WFE dibandingkan kelompok II yang diberikan terapi TENS dan WFE.

\section{Tabel 3}

Nilai VAS Sebelum Perlakuan Pada Kelompok I Dan II

\begin{tabular}{ccc}
\hline Sebelum & $\begin{array}{c}\text { Kelompok I } \\
\mathbf{n = 1 0}\end{array}$ & $\begin{array}{c}\text { Kelompok II } \\
\mathbf{n}=\mathbf{1 0}\end{array}$ \\
\hline Minimal & 60 & 60 \\
Maksim & 80 & 80 \\
Rerata & 71,00 & 67,00 \\
SD & $\pm 5,676$ & $\pm 9,487$ \\
\hline
\end{tabular}

1. Keadaan akhir subjek

Pengukuran post test dengan VAS

pada kelompok I (elektroakupunktur dan WFE) didapatkan hasil nilai VAS minimal $20 \mathrm{~mm}$, nilai VAS maksimal $40 \mathrm{~mm}$ dengan rerata $26,00 \mathrm{~mm}$. sedangkan pada kelompok II (TENS dan WFE) didapatkan hasil nilai VAS minimal $30 \mathrm{~mm}$, nilai VAS maksimal $50 \mathrm{~mm}$ dengan rerata $36,00 \mathrm{~mm}$. Dari data tersebut didapat rerata nilai VAS setelah perlakuan pada kedua kelompok relatif tidak jauh berbeda, dengan selisih rerata $10 \mathrm{~mm}$ lebih besar pada kelompok yang diberikan terapi elektroakupunktur dan WFE dibanding kelompok yang diberikan terapi TENS dan WFE.
Nilai VAS Setelah Perlakuan Pada Kelompok I dan Kelompok II

\begin{tabular}{ccc} 
Sesudah & $\begin{array}{c}\text { VAS (mm) } \\
\text { Kelompok I (n } \\
=\mathbf{1 0})\end{array}$ & $\begin{array}{c}\text { VAS (mm) } \\
\text { Kelompok II } \\
(\mathbf{n}=\mathbf{1 0})\end{array}$ \\
\hline Minimal & 20 & 30 \\
Maksimal & 40 & 50 \\
Rerata & 26 & 36 \\
SD & $\pm 6,992$ & $\pm 8,433$ \\
\hline 2. Selisih rerata keadaan awal \\
dengan keadaan akhir subjek \\
Pada penelitian ini diperoleh hasil \\
rerata masing - masing kelompok, dan \\
terdapat perbedaan rerata antara sebelum \\
dan sesudah perlakuan berupa terapi \\
elektroakupunktur dan WFE dengan \\
TENS dan WFE. Perubahan selisih rerata \\
nilai VAS pada kelompok I adalah 45 mm \\
sedangkan pada kelompok II adalah 31 \\
mm.
\end{tabular}

Tabel 5

Selisih Nilai Rerata VAS Kelompok I dan II

\begin{tabular}{cccc}
\hline & $\begin{array}{c}\text { Nilai rerata } \\
\text { sebelum } \\
\text { perlakuan }\end{array}$ & $\begin{array}{c}\text { Nilai rerata } \\
\text { setelah } \\
\text { perlakuan }\end{array}$ & Selisih \\
\hline Kel I & 71 & 26 & 45 \\
Kel II & 67 & 36 & 31 \\
\hline & Analisis statistik & yang digunakan
\end{tabular}

Analisis statistik yang digunakan dalam penelitian ini adalah untuk membuktikan hipotesis, uji hipotesis I dan II menggunakan uji Wilcoxon, sedangkan untuk uji hipotesis III menggunakan uji Mann-Whitney dan uji hipotesis IV menggunakan selisih rerata kelompok 1 dan 2 setelah diberikan perlakuan.

1. Uji prasarat

Penelitian ini menggunakan uji statistik non parametrik dikarenakan jumlah subjek hanya 20 orang atau kurang dari 50 subjek (Hastono, 2010). Kemudian dilakukan uji homogenitas data sebelum diberikan perlakuan (pre test) antara kelompok I dan II dengan menggunakan Mann-Whitney test, hasil uji tersebut akan

Tabel 4 
ada perbedaan jika nilai $\mathrm{p}<0.05$, namun pada penelitian ini didapatkan nilai $\mathrm{p}=$ 0,212 ( $p>0.05$ ) yang berarti tidak ada perbedaan yang bermakna (data homogen) antara kedua kelompok sebelum diberikan terapi elektroakupunktur dan WFE maupun TENS dan WFE.

2. Uji beda

a. Uji hipotesis I (uji beda pre - post test kelompok I)

Uji beda pre - post test pada kelompok I menggunakan Wilcoxon test, dengan nilai $\mathrm{p}=0,005(\mathrm{p}<0.05)$ yang berarti ada beda, dengan demikian ada pengaruh pemberian terapi elektroakupunktur dan WFE terhadap penurunan nyeri pada pasien nyeri punggung bawah miogenik.

b. Uji hipotesis II (uji beda pre - post test kelompok II)

Uji beda pre - post test pada kelompok II menggunakan Wilcoxon test, didapatkan nilai $\mathrm{p}=0,004(\mathrm{p}<0.05)$ yang berarti ada beda, dengan demikian ada pengaruh pemberian terapi TENS dan WFE terhadap penurunan nyeri pada pasien nyeri punggung bawah miogenik.

c. Uji hipotesis III (uji beda post kelompok I dan II)

Uji beda post test pada kelompok I dan kelompok II menggunakan MannWhitney test, didapatkan hasil nilai $\mathrm{p}=$ $0,017$ ( $p<0.05)$ yang berarti ada perbedaan yang bermakna antara kelompok I yang diberikan terapi elektroakupunktur dan WFE dengan kelompok II yang diberikan terapi TENS dan WFE. Dengan demikian ada perbedaan pengaruh antara pemberian terapi elektroakupunktur dan WFE dengan pemberian terapi TENS dan WFE terhadap penurunan nyeri pada pasien nyeri punggung bawah miogenik. d. Uji Hipotesis IV (uji untuk mengetahui terapi manakah yang lebih efektif)

Berdasarkan hasil uji beda post test kelompok I dan kelompok II ada perbedaan bermakna, artinya ada yang lebih baik antara pemberian terapi elektroakupunktur dan WFE dengan pemberian terapi TENS dan WFE terhadap penurunan nyeri pada pasien nyeri punggung bawah miogenik. Untuk mengetahui manakah terapi yang lebih efektif terhadap penurunan nyeri pada pasien nyeri punggung bawah miogenik adalah dengan melihat perubahan selisih rerata nilai VAS pre dan post terapi pada kelompok I adalah $45 \mathrm{~mm}$ sedangkan pada kelompok II adalah $31 \mathrm{~mm}$ yang berarti pemberian terapi pada kelompok I lebih efektif karena memiliki perubahan selisih rerata yang lebih besar dibandingkan kelompok II.

\section{PEMBAHASAN}

Pemberian terapi elektro akupunktur berpengaruh terhadap penurunan nyeri pada pasien nyeri punggung bawah miogenik, dibuktikan dengan uji Wilcoxon dan didapatkan hasil $p=0,005$. Pemberian elektroakupunktur menjadi terapi yang efektif, di mana mendorong produksi endorphin dan encephalins yang memiliki efek penurunan nyeri di tingkat sinaps (inhibisi nyeri di sinaps). Aplikasi elektroakupunktur juga dapat merangsang perbaikan sirkulasi darah melalui kontraksi otot yang lebih dalam sehingga dampak perbaikan sirkulasi darah dan relaksasi otot dapat lebih kuat dan cepat di area nyeri. Hasil ini sejalan dengan jurnal penelitian yang berjudul "Use of Electroacupuncture for Treatment of Chronic Sciatic Pain" dijelaskan bahwa 
telah terbukti dengan pemberian elektroakupunktur pada serabut saraf bermielin kecil yang terletak di otot dapat menghantarkan rangsangan ke sumsum tulang belakang, otak tengah dan hipofisis-hipotalamus sehingga menimbulkan efek analgesik dengan terlepasnya endorphine (Hollisaz, 2006).

Selanjutnya untuk pemberian terapi TENS juga berpengaruh terhadap penurunan nyeri pada pasien nyeri punggung bawah miogenik, dibuktikan dengan uji Wilcoxon diperoleh nilai $\mathrm{p}=$ 0,004 (ada pengaruh pemberian TENS terhadap penurunan nyeri punggung bawah miogenik). TENS dengan frekuensi rendah, intensitas tinggi yang merupakan rangsangan noxious akan merangsang serabut saraf A delta dan $C$ yang akan menyebabkan releasenya $\beta$ endhorpin di tingkat hipotalamus sehingga nyeri tidak dipersepsikan. Di samping itu dalam aplikasi TENS dengan frekuensi rendah, intensitas tinggi dapat menyebabkan timbulnya kontraksi otot sehingga dapat menurunkan nyeri melalui perbaikan sirkulasi darah dan metabolisme di area nyeri. Efektivitas pemberian terapi TENS dalam penelitian ini sejalan dengan jurnal penelitian yang berjudul "Electrical stimulation for chronic non-specific low back pain in a working-age population" dijelaskan bahwa telah terbukti dengan pemberian TENS akan merangsang sistem saraf melalui permukaan kulit yang telah terbukti efektif untuk menghilangkan nyeri (Thiese, et al 2013).

Selanjutnya didapatkan ada perbedaan pengaruh antara pemberian terapi elektroakupunktur dengan TENS terhadap penurunan nyeri pada pasien nyeri punggung bawah miogenik sebelum diberikan William Flexion Exercise, dibuktikan dengan hasil uji Mann-
Whitney dan diperoleh nilai $\mathrm{p}=0,017$. Hal ini menunjukkan adanya perbedaan pengaruh antara pemberian terapi elektroakupunktur dengan TENS sebelum diberikan William Flexion Exercise yang dibuktikan dengan selisih perubahan rerata pre dan post nilai VAS dengan hasil rerata kelompok I lebih besar daripada kelompok II sehingga dapat disimpulkan bahwa kelompok I memiliki efektivitas terapi lebih baik daripada kelompok II.

Dalam penelitian ini didapatkan hasil elektroakupunktur lebih efektif daripada TENS dibuktikan dengan melihat perubahan selisih rerata nilai VAS pre dan post terapi pada kelompok I adalah $45 \mathrm{~mm}$ sedangkan pada kelompok II adalah 31 mm. Pemberian terapi TENS berupa stimulus noxious akan meningkatkan vaskularisasi darah melalui timbulnya kontraksi otot lebih superficial (saat stimulasi berlangsung) sehingga akan terjadi peningkatan vaskularisasi darah dan rileksasi otot di area lesi. Sedangkan pada penusukan jarum akupunktur pada titik trigger point menyebabkan luka di area punggung bawah dan mengakibatkan terjadinya inflamasi lokal pada kulit (dermatom), pembuluh darah (angiotom), otot (myotom) yang akan diikuti terlepasnya beberapa senyawa kimia (prostaglandin, hystamin, bradykinin dan cytokinin, substance-p) maka akan memicu terjadinya peningkatan proses vaskularisasi melalui timbulnya kontraksi otot yang lebih dalam, sehingga akan terjadi peningkatan proses vaskularisasi darah dan rileksasi otot lebih kuat dan cepat di area lesi. Hal inilah yang menyebabkan elektroakupunktur memiliki efek jangka panjang dalam menurunkan nyeri pada pasien nyeri punggung bawah miogenik sehingga menjadikan elektroakupunktur lebih efektif 
dibandingkan TENS. Hal ini sejalan dengan sebuah jurnal yang berjudul "Randomised Controlled Trial Comparing the Effectiveness of Electroacupuncture and TENS for Low Back Pain" yang menjelaskan bahwa pemberian elektroakupunktur dirasakan lebih efektif dalam menurunkan nyeri dibandingkan pemberian TENS akibat dari dampak elektroakupunktur yang merangsang terutama lepasnya endhorpin di hipotalamus dan terdapat dua tingkat perbaikan yaitu pada tingkat lokal terjadi perbaikan vaskularisasi dan metabolisme, sedangkan pada tingkat central terjadi penurunan nyeri dengan mekanisme $B$ endorphin sehingga menyebabkan efek elektroakupunktur bisa lebih lama dirasakan (Tsukayama et al, 2002).

Adapun keterbatasan dalam penelitian ini meliputi : (1) subjek yang digunakan dalam penelitian ini sedikit sehingga kurang representasi dalam menggeneralisir hasil dari penelitian, (2) peneliti tidak dapat mengontrol variabel pengganggu yaitu aktifitas subjek sehari hari yang berpengaruh terhadap hasil penelitian yaitu penurunan kualitas nyeri penderita nyeri punggung bawah miogenik.

Berdasarkan hasil analisis dan pembahasan pada penelitian ini, maka kombinasi elektroakupunktur, TENS, dan William Flexion Exercise dapat membantu dalam penurunan nyeri pada pasien NPB myogenik. Namun pemberian elektroakupunktur dan William Flexion Exercise lebih disarankan untuk implikasi klinis karena terbukti lebih efektif menurunkan nyeri dibandingkan pemberian TENS dan William Flexion Exercise pada pasien nyeri punggung bawah miogenik.

\section{KESIMPULAN DAN SARAN}

Penelitian berjudul "Perbedaan Efektivitas Elektroakupunktur dengan TENS Terhadap Penurunan Nyeri pada Pasien Nyeri Punggung Bawah Miogenik Sebelum Diberikan William Flexion Exercise" diperoleh kesimpulan: (1) ada pengaruh terapi elektroakupunktur terhadap penurunan nyeri pada pasien nyeri punggung bawah miogenik sebelum diberikan William Flexion Exercise ( $\mathrm{p}$ $=0,005$ ), (2) ada pengaruh pemberian terapi TENS terhadap penurunan nyeri pada pasien nyeri punggung bawah miogenik sebelum diberikan William Flexion Exercise $(\mathrm{p}=0,004),(3)$ ada perbedaan pengaruh antara pemberian terapi elektroakupunktur dengan pemberian terapi TENS terhadap penurunan nyeri pada pasien nyeri punggung bawah mogenik sebelum diberikan William Flexion Exercise $(\mathrm{p}=$ 0,017), (4) pemberian terapi elektroakupunktur lebih efektif daripada pemberian terapi TENS terhadap penurunan nyeri pada pasien nyeri punggung bawah myogenik sebelum diberikan William Flexion Exercise dibuktiklan dengan selisih rerata nilai VAS pre dan post kelompok I lebih besar daripada kelompok II (kelompok I $=45$ $\mathrm{mm}$, kelompok II =31 mm).

Disarankan agar dilakukan penelitian lebih lanjut dengan mempertimbangkan: (1) memperbanyak subjek penelitian, (2) mengontrol aktivitas di luar penelitian dengan pemberian edukasi kepada subjek penelitian, (3) karakteristik subyek penelitian dengan jenis kelamin yang berbeda sehingga lebih representasi dalam aplikasi hasil penelitian. 


\section{DAFTAR RUJUKAN}

Gadsby, J. G. and M. W. Flowerdew (2000). "Transcutaneous electrical nerve stimulation and acupuncturelike transcutaneous electrical nerve stimulation for chronic low back pain." Cochrane Database Syst $\operatorname{Rev}(2): \mathrm{CD} 000210$.

Hollisaz, M., (2006); Use of Electroacupuncture for Treatment of Chronic Sciatic Pain; The Internet Journal of Pain Symptom Control and Palliative Care, Vol 2 Number 1.

Huldani, (2012); Nyeri Punggung, Universitas Lambung Mangkurat Fakultas Kedokteran Banjarmasin, Kalimantan, hal.5.

Johnson, M., (2015); Transcutaneus Electrical Nerve Stimulation; diakses tanggal 13/05/2015 dari www.googlescholar.co.id.

Khadilkar, A., et al. (2005).

"Transcutaneous electrical nerve stimulation for the treatment of chronic low back pain: a systematic review." Spine 30(23): 2657-66.

Kurniasih, E., (2013); Penambahan Terapi Latihan Mc. Kenzie pada Intervensi SWD, TENS, dan Massage dapat Menurunkan Nyeri Pinggang pada Kasus Low Back Pain, Universitas Udayana, Denpasar-Bali, hal.2-3.

Paliyama, M., (2004); Perbandingan Efek Terapi Arus Interferensi dengan TENS dalam Pengurangan Nyeri pada Penderita Nyeri Punggung Bawah Muskuloskeletal; Universitas Diponegoro, Semarang, hal.9.

Pramita dkk, (2015); Core Stability Exercise lebih baik Meningkatkan
Aktivitas Fungsional daripada William's Flexion Excercise pada Pasien Nyeri Punggung Bawah Miogenik; Sport and fitness journal, volume 3, no.1.

Priyambodo. H., (2009); Penatalaksanaan Fisioterapi pada kondisi Low Back Pain Miogenik di RSUD Boyolali; Universitas Muhammadiyah Surakarta, Surakarta, hal.20.

Purnama, S.M, (2010); Faktor-Faktor yang Mempengaruhi Insiden Nyeri Punggung Bawah (low back pain) pada pasien Rumah Sakit Immanuel Bandung periode Januari-Desember 2009, Universitas Kristen Maranatha, Bandung, hal. 4.

Saputra. K., (2011); Biofisika Akupunktur dalam Konsep Kedokteran Energi, Salemba Medika, Jakarta, hal.105106.

Syaifulloh, M., (2010); $\quad$ Pengaruh Rangsang Elektroakupunktur terhadap Memori kerja tikus putih (rattus novergicus) yang dipapar Stres Kronik; Universitas Sebelas Maret, Surakarta, hal.22.

Tholib, A., (2010); Penatalksanaan Fisioterapi pada Low Back Pain Miogenik di RST. Dr. Soejono Magelang, Universitas Muhammadiyah Surakarta, Surakarta, hal.3. 